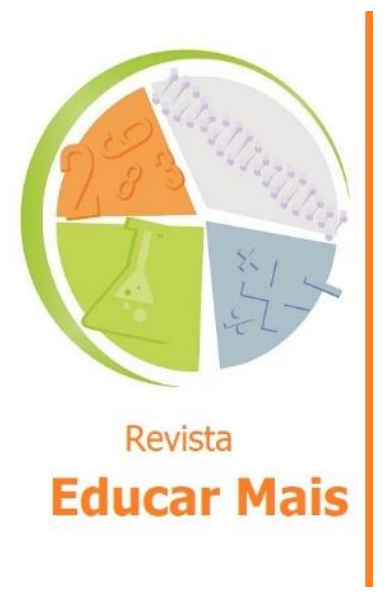

\section{Reflexões sobre as práticas de letramentos passíveis de transformações identitárias de profissionais que atuam como docentes na educação profissional}

\author{
Reflections on the practices of lettering that may be identity \\ transformed by professionals who act as teachers in professional \\ education
}

\begin{abstract}
Reflexiones sobre las prácticas de letras que pueden transformar la identidad por profesionales que actúan como profesores de educación profesional
\end{abstract}

Viviam Lorena Pereira Pereira ${ }^{1}$; Veronice Camargo da Silva ${ }^{2}$

\title{
RESUMO
}

O presente artigo tem como objetivo reflexionar sobre as práticas de letramentos passíveis de transformações identitárias de profissionais que atuam como docentes na Educação Profissional na cidade de Bagé. A pesquisa tem caráter qualitativo e caracteriza-se como um estudo de caso. As estratégias metodológicas adotadas foram a aplicação e análise de um questionário a três professores atuantes no ensino técnico/profissionalizante. 0 estudo apoia-se teoricamente em autores como Nóvoa (2007, 2009), para falar de formação docente, nas palavras de Hall $(2007,2011)$, para abordar as questões de identidade docente e pauta-se nos Novos Estudos de letramentos propostos por Street $(1984,2006)$, Kato (1986) para compreender os letramentos existentes no fazer docente. Os resultados obtidos nesse estudo apontam as múltiplas transformações que atravessam os sujeitos quanto a sua identidade. Ainda foi possível visualizar que essas metamorfoses ocorrem de acordo com a realidade e contexto vividos e que destes emergem distintas práticas de letramentos.

Palavras-chave: Educação Profissional; Formação docente; Identidade docente; Letramentos.

\begin{abstract}
This article aims to reflect on the literacy practices that can be transformed by professionals who work as teachers in technical / vocational education at a technical school in the city of Bagé. The research has a qualitative character and is characterized as a case study. The methodological strategies were given through the application and analysis of a questionnaire to three teachers working in technical / vocational education. The study is theoretically based on authors such as Nóvoa (2007, 2009), to speak about teacher training, in the words of Hall $(2007,2011)$, to address issues of teacher identity and is based on the New Studies of literacies proposed by Street $(1984,2006)$, Kato (1986) to understand the literacies that exist in teaching. The results obtained in this study point out the multiple transformations that the subjects go through in terms of their identity and that these metamorphoses occur according to the reality and context experienced and that different literacy practices emerge from these.
\end{abstract}

Keywords: Technical/vocational education; Teacher training; Teacher identity; Literacies.

\section{RESUMEN}

Este artículo tiene como objetivo reflexionar sobre las prácticas de alfabetización que pueden ser transformadas por los profesionales que se desempeñan como docentes en la educación técnica / vocacional en una escuela técnica de la ciudad de Bagé. La investigación tiene un carácter cualitativo y se caracteriza por ser un estudio

\footnotetext{
${ }^{1}$ Pedagoga e Especialista em Gestão de Currículo na Formação Docente. Professora de Educação Infantil no município de Bagé/RS - Brasil. E-mail: viviamlorenap@gmail.com

2 Doutora em Linguística aplicada e Professora adjunta da Universidade Estadual do Rio Grande do Sul (UERGS), Bagé/RS - Brasil. E-mail: veronice-silva@uergs.edu.br
} 
de caso. Las estrategias metodológicas se dieron a través de la aplicación y análisis de un cuestionario a tres docentes que trabajan en la educación técnica / profesional. El estudio se basa teóricamente en autores como Nóvoa (2007, 2009), para hablar de formación docente, en palabras de Hall (2007, 2011), para abordar cuestiones de identidad docente y se basa en los Nuevos Estudios de alfabetizaciones propuestos por Street (1984, 2006), Kato (1986) para comprender las alfabetizaciones que existen en la docencia. Los resultados obtenidos en este estudio señalan las múltiples transformaciones que atraviesan los sujetos en cuanto a su identidad y que estas metamorfosis ocurren de acuerdo a la realidad y contexto vivido y que de ellas surgen diferentes prácticas de alfabetización.

Palabras clave: Educación técnica/profesional; Formación docente; Identidad docente; Alfabetizaciones.

\section{INTRODUÇÃO}

Uma das discussões mais relevantes no campo educacional brasileiro é a questão da formação pedagógica dos professores atuantes nos diferentes níveis de ensino, esta formação envolve um ato de reconsiderar constantemente o fazer docente (NÓVOA, 2009), diante das muitas inquietudes que permeiam a profissão.

Na educação técnica /profissional, a formação pedagógica é um campo pouco explorado, sendo essa, uma busca que recai, muitas vezes, sobre os próprios profissionais que atuam nessa modalidade de ensino.

O interesse em propor este estudo partiu de uma inquietação frente às ações dos educadores em buscar caminhos que os levem, não apenas à qualificação necessária para atuação docente, mas também, à reflexão sobre suas práticas e à ressignificação do exercício da docência.

Desta forma, propor um estudo que evidencie os saberes docentes no campo da formação continuada pode levar a ressignificações da prática cotidiana desses profissionais ao se desafiarem em um universo complexo que envolve os distintos saberes que compõem as salas de aula e os alunos que ali estão em busca de qualificação profissional.

Frente a essas inquietações, a presente pesquisa conduz a problematizar até que ponto as práticas de letramentos podem contribuir com as possíveis transformações no que se refere à construção da identidade docente. Para tanto, o objetivo geral constitui-se em reflexionar sobre as práticas de letramentos passíveis de transformações identitárias de profissionais que atuam como docentes na Educação Profissional. Os objetivos específicos são: (a) identificar os caminhos de formação inicial e continuada percorridos pelos docentes; (b) constatar as possíveis transformações identitárias dos docentes com relação à prática docente; (c) reconhecer qual/is modelo/s de letramentos estão presentes nas práticas pedagógicas.

Este estudo caracterizou-se como uma pesquisa de análise qualitativa, inserida no campo das ciências humanas e debruçada sobre um estudo de caso que "visa conhecer em profundidade o como e o porquê de uma determinada situação que se supõe ser única em muitos aspectos, procurando descobrir o que há nela de mais essencial e característico" (FONSECA, 2002, p.33). Tais fatos que envolvem a formação pedagógica de profissionais que atuam na Educação Profissional, bem como os aspectos que caracterizam o desenvolvimento dos letramentos desses profissionais de acordo com a coleta de dados, deu-se por meio de um questionário aplicado a três docentes que atuam no ensino técnico municipal de Bagé/RS.

Com o propósito de orientar o leitor, o artigo irá apresentar sessões relevantes a serem abordadas nesta pesquisa, portanto, debruça-se nas considerações de Gatti (1996), Nóvoa $(2007,2009)$, Tardif (2014), Oliveira $(2006,2010)$ para aprofundar sobre a formação docente e o quanto a mesma está diretamente ligada ao exercício da docência. Para abordar os conceitos de letramentos e como esses conceitos se fazem presentes na interpretação das ações cotidianas do fazer docente, tem-se o apoio de autores como Kato (1986), Street (1984), Tfouni (1995). Com base em Hall (2007,2011), Proença e Mello (2009) e Bauman(2010), discutimos as 
questões que englobam a construção da identidade docente, visto que este é um processo de constante transformação.

\section{FAZERES E PENSARES: UMA REFLEXÃO SOBRE A FORMAÇÃO DOCENTE}

A formação docente é uma temática bastante discutida na área da educação no que tange aos cursos de formação de professores ou, ainda, de profissionais que exercem à docência. Desta forma, passouse a entender o professor como um ser com necessidades de buscar referências para suas ações pedagógicas. Os princípios que fomentam as práticas docentes são tanto no âmbito do conhecimento profissional específico como nos desdobramentos que o ofício docente acarreta. Nesse sentido, as características do profissional da educação vão sendo desenhadas gradativamente, considerando suas trajetórias e vivências, pois, segundo Gatti (1996) a edificação do perfil do professor se entrelaça com as relações profissionais e interpessoais destes sujeitos.

Embora discussões sobre a formação pedagógica dos professores, em especial, sobre professores atuantes na Educação Profissional, sejam recentes, esse campo é de extrema relevância para a prática docente, portanto, caracteriza-se por ser um terreno de muitas incertezas e indagações no tocante ao domínio do fazer docente, bem como seus desafios e definições mais sólidas. Ser professor é um ato de ensinar que se constrói no cotidiano e é aprendido paulatinamente e, esta aprendizagem, sofre mudanças constantes (NÓVOA, 2009) que necessita de uma reflexão frente a essas mudanças como forma de definir os rumos da prática educacional contextualizada.

Se por um lado, no cotidiano do exercício da docência, mais precisamente, na reflexão da própria atuação ou na troca de saberes com os pares, constitui-se o papel do professor, por outro, a formação docente pode ser vista como espaço para efetivar a apropriação de saberes que fomentam a prática docente. De acordo com Tardif,

Nenhum saber é por si mesmo formador. Os mestres não possuem mais saberesmestres (filosofia, ciência positiva, doutrina religiosa, sistema de normas e de princípio, etc.) cuja posse venha garantir sua mestria: saber alguma coisa não é mais suficiente, é preciso também saber ensinar. O saber transmitido não possui, em si mesmo, nenhum valor formador; somente a atividade de transmissão lhe confere esse valor. Em outras palavras, os mestres assistem a uma mudança na natureza de sua mestria: ela se desloca dos saberes para os procedimentos de transmissão dos saberes. (TARDIF, 2014, p.44).

Ao refletir sobre as palavras de Tardif (2014), é possível compreender que há em algum momento no exercício da docência uma tomada de consciência por parte dos professores que constitui uma mola propulsora levando-os a busca de novas formas de aprender e ensinar.

Caracterizando, assim, de forma mais estreita e intensa, o ofício da profissão docente, colocando o educador como sujeito protagonista de sua própria formação e consequentemente promovendo sua autonomia profissional.

Desta forma, emergem novos pensares sobre o fazer docente, é através da reflexão sobre a própria atuação que se re(constrói) o trabalho na docência fazendo com que o ambiente em que as vivências pedagógicas ocorrem seja o palco que sediará uma transformação e uma intervenção no viés de promover um significado real sobre a prática pedagógica. 
O presente estudo debruça-se sobre a formação de professores atuantes na Educação Profissional e algumas especificidades desta modalidade de ensino. À luz dos documentos legais, o termo Educação Profissional está presente na Lei de Diretrizes e Bases da Educação Nacional LDB, No 9.394/96, como uma modalidade da Educação Básica, que pode ser realizada sincronicamente ou subsequentemente à conclusão do ensino médio como forma de conduzir o aluno a uma habilitação profissional. Sobre esta modalidade, o Art. 36-B determina como deve acontecer:

Art. 36-B. A educação profissional técnica de nível médio será desenvolvida nas seguintes formas: (Incluído pela Lei no 11.741, de 2008)

I -articulada com o ensino médio; (Incluído pela Lei no 11.741, de 2008)

II - subsequente, em cursos destinados a quem já tenha concluído o ensino médio. (Incluído pela Lei no 11.741, de 2008)

Parágrafo único. A educação profissional técnica de nível médio deverá observar: (Incluído pela Lei no 11.741, de 2008)

I - os objetivos e definições contidos nas diretrizes curriculares nacionais estabelecidas pelo Conselho Nacional de Educação;

II - as normas complementares dos respectivos sistemas de ensino;

III - as exigências de cada instituição de ensino, nos termos de seu projeto pedagógico.

Sobre as discussões referentes à formação dos docentes que atuam na Educação Profissional, Oliveira (2010) aponta que a carência de uma formação pedagógica que contemple essa modalidade de ensino tem uma conexão direta com a ideia de que a experiência profissional assume um caráter compensatório em relação a formação acadêmica.

Ao analisar a situação em relação à formação docente voltada aos profissionais do ensino Educação Profissional, é possível se deparar com uma cultura de raízes profundas quando percebe o professor como um transmissor de um saber específico a sua área de atuação ou disciplina ministrada, apontamentos estes sinalizados na fala de Oliveira

[...] há uma tradição na área no sentido de se considerar que, para ser professor, o mais importante é ser profissional da área relacionada à(s) disciplinas que vai lecionar ou leciona. O professor do ensino técnico não é concebido como um profissional da educação, mas um profissional de outra área e que nela leciona (OLIVEIRA, 2006, p. $5)$.

No tocante do exposto, há a necessidade em conhecer os perfis e as trajetórias destes profissionais que decidiram assumir a docência na Educação Profissional e como estes se percebem sujeitos desse processo de transformação profissional, observando, também, a maneira como os mesmos realizam suas escolhas para o trabalho pedagógico no que tange à aquisição de conhecimentos por parte de seus alunos.

\section{IDENTIDADE DOCENTE: UM PERCURSO DE TRANSFORMAÇÃO E FORMAÇÃO DO SER PROFESSOR}

A profissão docente é caracterizada por inúmeros movimentos que a transformam no cotidiano da docência. Logo, as identidades que ali estão a se construírem sofrem mudanças constantes oriundas das distintas relações que acontecem nos espaços escolares. Portanto, por se tratar de uma profissão 
que estabelece relações e interações com outros indivíduos, está carregada de significados afetivos, emocionais e sociais.

Desta forma, é necessário refletir sobre as mudanças que ocorrem no processo de profissionalização docente e as influências que tais transformações acarretam à construção de sua identidade vista como mutável e contínua por Dubar (2006), contribuindo com as metamorfoses sociais e individuais que os sujeitos sofrem ao longo de suas trajetórias pessoais e profissionais.

Para Hall (2011), a identidade é construída das múltiplas experiências que o indivíduo tem ao longo da sua trajetória de vida. Refletir sobre a identidade nessa ótica nos leva a pensar como a identidade dos sujeitos se constituíam até o presente momento. Assim nos debruçamos sobre as colocações de Hall (2011) quando este apresenta três concepções sobre a identidade.

A primeira referente ao sujeito do iluminismo, a qual destaca a pessoa humana como um ser centrado na capacidade da razão. A segunda refere-se ao sujeito sociológico. Nesta concepção começa a surgir um entendimento sobre a complexidade do mundo moderno na qual percebe-se que os sujeitos eram formados na relação com "outras pessoas importantes para ele "(HALL, 2011, p. 11), que lhe apresentavam o mundo dos valores sociais. Na terceira concepção, remete-se ao sujeito pósmoderno, com um deslocamento identitário que se modifica de acordo com as identificações do sujeito nos distintos meios no qual está imerso, assim segundo Hall

Assim, em vez de falar da identidade como uma coisa acabada, deveríamos falar de identificação, e vê-la como um processo em andamento. A identidade surge não tanto da plenitude da identidade que já está dentro de nós como indivíduos, mas de uma falta de inteireza que é "preenchida a partir de nosso exterior, pelas formas através das quais nós imaginamos ser vistos por outros. (HALL,2011, p. 39).

De acordo com o autor podemos considerar que a identidade é constituída através do partilhamento de vivências e interrelações ao longo da trajetória pessoal e profissional dos sujeitos. Por sua vez, para compreendermos a identidade na totalidade, faz-se necessário "compreender o mundo e a humanidade em movimento, com suas contradições. Ao mesmo tempo em que o ser tem suas características que o individualizam, também possui as que o universalizam (PROENÇA E MELLO, 2009, p.56)".

A partir destes apontamentos podemos considerar que as identidades docentes estão em constante processo de re (significação) e re (estruturação), buscando concepções de como ser professor, pois o perfil de uma identidade homogênea e estável (HALL,2007) abre espaço para a construção de um ser fragmentado que se apropria dos espaços em que ocupa e dele elabora novos sentidos de ser e agir como profissional e como sujeito

Neste contexto, faz-se importante discutir a identidade desse profissional/docente que assume as posturas de professor e o quanto ela impregna suas ações pedagógicas no que tange a sua formação e como os aspectos dos letramentos estão presentes nas suas interpretações cotidianas.

Assim, como na constituição dessas identidades docentes que são adquiridas, como destaca (BAUMAN, 2010 p. 54) através do ato de libertar a própria personalidade por não bastar ser o que todo mundo já apresenta ser, elaborando novas habilidades relacionadas ao próprio trabalho. 


\section{LETRAMENTOS}

A leitura e a escrita são os caminhos de comunicação que dominam o mundo desde sua origem. 0 homem faz o uso da linguagem oral e escrita para representar suas emoções, fazer novas descobertas, construir conceitos e conhecimentos. Todavia, compreender o papel da leitura e da escrita no contexto social gradativamente foi se constituindo primordial na área da educação, juntamente com a leitura e a escrita abre-se o campo dos debates para analisar como esse processo de aquisição da leitura e da escrita ocorrem e se consolidam ao logo da trajetória de todos os indivíduos.

Nesse viés, surgem estudos para compreender como a leitura e a escrita são concebidas nas mais variadas esferas cotidianas. Este estudo busca enfatizar a relevância da leitura e da escrita no contexto educacional. Pautando-se no entendimento que os educadores possuem sobre os processos de letramentos que os constituem enquanto docentes.

Para que possamos entender como a leitura e a escrita são concebidas, recorremos ao campo dos estudos referidos ao letramento. Este termo vem auxiliar os estudiosos de linguística para que possam entender a forma como interpretamos o universo da decodificação do mundo da leitura e da escrita.

Os estudos no campo do letramento surgem através dos estudos de Kato (1986). A autora faz uso do termo letramento para apresentar as questões que estão presentes na psicolinguística e que se configuram os processos de aprendizagem da linguagem.

Desde o início dos estudos sobre letramento, muitas concepções e compreensões foram debatidas por distintos estudiosos. Dentre eles Tfouni (1995), que evidencia o aspecto de que o termo letramento está diretamente ligado ao uso social da leitura e da escrita. Salientando que este caminho da elaboração da leitura e da escrita possui marcas e características das sociedades ágrafas.

As múltiplas faces do letramento podem ainda serem evidenciadas nos estudos de Kleiman ao destacar que o letramento é "um conjunto de práticas sociais que se usa a escrita enquanto sistema simbólico e enquanto tecnologia, em contextos específicos para objetivos específicos" (KLEIMAN, 1995, p.19). Dessa forma, a autora destaca a capacidade de entendimento que os sujeitos apresentam em cada distinta situação que vivenciam e que, dependendo destas interpretações, novas práticas de letramento se constituem a cada novo contexto vivenciado.

O campo dos Novos Estudos de Letramento propostos por Street (1984) abraça um olhar mais crítico e reflexivo sobre as questões que envolvem os estudos da linguagem e dos processos de elaboração da leitura e da escrita, sendo sobretudo um processo dinâmico de apropriação e intenção nas ações dos indivíduos.

Para Street (2006), são os aspectos sociais, políticos, econômicos, culturais e históricos que contribuem para as práticas sociais de letramento. E os sujeitos, no instante em que se apoderam e interpretam essas diferentes questões sociais demonstram o quanto estão envoltos pelas transformações sociais e, a forma como as interpretam, é que constituem seus diferentes processos de letramento. Assim sendo, as práticas de letramento no panorama social são um conjunto de fatos sociais, em que os indivíduos se empoderam de maneira ideológica e não em uma condição de neutralidade. 
Strret (1984) defende o uso da palavra letramentos no plural, pois estes envolvem múltiplos sentidos e habilidades no campo da leitura e da escrita, este estudo se ancora na visão do letramento autônomo e ideológico, para compreender como os docentes pensam, planejam e atuam frente as diferentes formas de ser, pensar e viver no contexto social. O autor aponta que o modelo autônomo de letramento envolve as capacidades individuais que são adquiridas de maneira que independem do contexto em que são vivenciadas. Em contrapartida, o modelo ideológico traz um olhar mais sensível, ao considerar os aspectos sociais e culturais em que o indivíduo está inserido.

O modelo ideológico defende que as interações sociais são fatores determinantes para as construções das relações de poder que estão diretamente conectadas com as práticas sociais da leitura e da escrita. Escreve o autor (2003, p.9):

[...] os modelos jamais foram propostos como opostos polares: em vez disso, o modelo ideológico de letramento envolve o modelo autônomo. A apresentação do letramento como sendo "autônomo" é apenas uma das estratégias ideológicas empregadas em associação ao trabalho no campo do letramento, que em realidade disfarça a maneira em que a abordagem supostamente neutra efetivamente privilegia as práticas de letramento de grupos específicos de pessoas. Nesse sentido, o modelo autônomo mostra-se profundamente ideológico. Ao mesmo tempo, o modelo ideológico consegue perceber as habilidades técnicas envolvidas, por exemplo, na decodificação, no reconhecimento das relações entre fonemas e grafemas e no engajamento nas estratégias aos níveis de palavras, sentenças e de textos [...]. Entretanto, o modelo ideológico reconhece que essas habilidades técnicas estão sempre sendo empregadas em um contexto social e ideológico, que dá significado às próprias palavras, sentenças e textos com os quais o aprendiz se vê envolvido. (STREET, 2003, p.9).

Portanto, fica evidente que ambos os processos de letramento se complementam. Assim, necessitamos compreender o sistema formal de leitura e escrita que adquirimos ao longo da trajetória escolar.

Todavia, é fundamental compreender que para a aquisição singular do sistema de escrita o modelo ideológico está em paralelo ao modelo autônomo, pois as singularidades e o contexto em que estamos imersos contribuem de forma direta para a concepção letrada que construímos cotidianamente.

\section{PERCURSO METODOLÓGICO}

Metodologicamente esta pesquisa é de natureza qualitativa e está inserida no campo das ciências humanas. A pesquisa qualitativa fundamenta-se pela relevância de explicar o "porquê das coisas" (GERHARDT e SILVEIRA,2009).

Seu desenvolvimento está voltado para os aspectos da realidade e tem como objetivo analisar as relações dos processos que ocorrem durante o estudo, buscando compreender, descrever e explicar.

Como evidencia Gerhardt e Silveira, 2009:

As características da pesquisa qualitativa são: objetivação do fenômeno; hierarquização das ações de descrever, compreender, explicar, precisão das relações entre o global e o local em determinado fenômeno; observância das diferenças entre o mundo social e o mundo natural; respeito ao caráter interativo entre os objetivos buscados pelos investigadores, suas orientações teóricas e seus dados empíricos; busca de resultados os mais fidedignos possíveis; oposição ao pressuposto que 
defende um modelo único de pesquisa para todas as ciências. (GERHARDT e SILVEIRA,2009, p.32)

A pesquisa foi realizada em uma instituição pública de Educação Profissional situada no centro da cidade de Bagé/RS. Essa instituição tem 63 anos de atuação na comunidade bajeense, sendo a única a ofertar cursos profissionalizantes totalmente gratuitos, de forma subsequente ao Ensino Médio, nas áreas de Administração, Contabilidade, Secretariado e Gestão Imobiliária.

Os cursos são oferecidos em turno noturno e dividido em quatro ciclos semestrais, sendo o quarto destinado a parte prática que configura em estágio não remunerado em empresas locais. A forma de ingresso nesses cursos se dá através de sorteio público que ocorre semestralmente.

A referida escola atende cerca de 1,2 mil alunos, sendo 750 no ensino fundamental diurno e 450 da Educação Profissional oriundos não só da cidade, também de municípios vizinhos.

Anualmente a escola forma em média 100 alunos em seus cursos técnicos e muitos destes já iniciam suas atividades profissionais antes mesmo da conclusão do curso em oportunidades de estágio e propostas profissionais que surgem no decorrer de seus estudos, evidenciando assim a importância dessa instituição para a cidade e a região, como também para o desenvolvimento pessoal e profissional de seus alunos.

A coleta de dados aconteceu através do uso de questionário, elaborado com questões diretas e dissertativas acerca da prática pedagógica dos educadores participantes da pesquisa, bem como, os caminhos que os levaram até a atuação docente.

Esta pesquisa baseia-se num estudo de caso com o propósito de realizar uma análise referente às vivencias dos profissionais que participam desde estudo e como estas vem ou não a contribuir para as transformações dos mesmos frente a atuação docente.

Segundo Prodanov e Freitas, 2013:

O estudo de caso consiste em coletar e analisar informações sobre determinado indivíduo, uma família, um grupo ou uma comunidade, a fim de estudar aspectos variados de sua vida, de acordo com o assunto da pesquisa. É um tipo de pesquisa qualitativa e/ou quantitativa, entendido como uma categoria de investigação que tem como objeto o estudo de uma unidade de forma aprofundada, podendo tratar-se de um sujeito, de um grupo de pessoas, de uma comunidade etc. São necessários alguns requisitos básicos para sua realização, entre os quais, severidade, objetivação, originalidade e coerência. (PRODANOV e FREITAS, 2013 p.60).

Para compor esse estudo, escolhemos três professores atuantes da Educação Profissional pela relevância de suas caminhadas profissionais dentro do cenário educacional, visto que todos os professores participantes são oriundos de cursos específicos de áreas distintas, mas não tinham formação em licenciatura, que é base para a atuação docente.

Para a melhor compreensão, os professores serão nomeados como professor(a) J, F e S, sendo duas professoras J e $\mathrm{F}$ e um professor $\mathrm{S}$.

O professor $\mathrm{S}$ tem 43 anos de idade e atua há 10 anos como professor no ensino técnico. É licenciado em Administração de Empresas e Recursos Humanos, MBA em Gestão de Recursos Humanos, especialista em Docência no Ensino Superior, em Gestão Escolar e Orientação Educacional, além de 
atuar como gestor na Escola Técnica Municipal 2015/2020 e como coordenador de uma Universidade EaD polo Bagé/ RS.

A professora $\mathrm{F}$ tem 35 anos de idade e atua há 10 anos como professora no ensino técnico. Possui formação em Comunicação Social- Habilitação em Jornalismo, especialista em Comunicação e Política. Além de ser professora de comunicação no ensino técnico, também atua como Analista em comunicação na Câmara de vereadores de Bagé e repórter na TV Câmara de Bagé.

A professora J tem 33 anos e há 8 anos atua como professora no ensino técnico. Possui formação em Psicologia, especialista em Neuropsicopedagogia e Educação Especial Inclusiva e é mestranda em Ensino (2019/2021).

\section{CAMINHOS À FORMAÇÃO DOCENTE}

O processo de formação profissional de educadores é um percurso longo e de muitas inquietações acerca da complexidade que o ofício docente acarreta aos professores que assumem tal responsabilidade, sendo esse um processo de adaptação, re (construção) e evolução tanto pessoal quanto profissional dos indivíduos, pois assim como a vida, a trajetória profissional também se caracteriza pela constante formação.

Nesse sentido, a formação inicial, continuada e permanente dos professores indica um processo dinâmico do fazer docente e a este confere a singularidade pessoal de sua história e trajetória de vida. Em outras palavras, podemos dizer que se trata de um ato de reflexão da própria atuação, bem como os múltiplos contextos em que esta atuação se desenvolve, seja na busca de estratégias, modelos e respostas para trabalho pedagógico ou ainda significados que fomentem sua ação educativa.

Ao pensarmos na formação pedagógica de professores atuantes da Educação Profissional devemos considerar a complexidade que há nessa modalidade de ensino no que tange à qualificação profissional.

Visto que há carência de formações específicas para esses profissionais da Educação Profissional, cabe destacar a relevância de formar profissionais aptos a desenvolver um trabalho crítico, reflexivo e contextualizado com a sua realidade.

Corroborando com as palavras Nóvoa:

Formar-se supõe troca, experiência, interações sociais, aprendizagens, um sem-fim de relações. Ter acesso ao modo como cada pessoa se forma é ter em conta a singularidade de sua história e sobretudo o modo singular como age, reage e interage com os seus contextos. Um percurso de vida é assim um percurso de formação, no sentido em que é um processo de formação. (NÓVOA, 2007, p. 115)

Assim sendo, se faz necessário compreender que as múltiplas trans(formações) que atravessam os sujeitos estão carregadas de complexidade e que este processo de formação produz distintas formas de agir e reagir diante das pluralidades e contextos a que estejam inseridos. Deste modo, é fundamental pensar numa formação docente significativa e inovadora, que de fato conduza o educador a consciência de ser o protagonista de sua formação.

Para tanto, quando questionados sobre a necessidade de buscar atualização em formações continuadas para dar conta do exercício da docência, sobre qual ou quais cursos foram realizados nos últimos 5 anos e em que medida, essas formações contribuíram para sua prática, obtivemos o seguinte retorno dos participantes: 


\begin{tabular}{|l|l|}
\hline Professora J & $\begin{array}{l}\text { Sim, senti necessidade, pois não tinha formação na área da educação e acabei me } \\
\text { tornando professora do ensino técnico. Fiz parte do PARFOR (2016-2017), na } \\
\text { Universidade Estadual do Rio Grande do Sul. Ela contribuiu muito instrumentalizando } \\
\text { minha práxis, por conhecer estratégias de ensino e formas diferenciadas de avaliação, } \\
\text { que era algo que me inquietava, sempre tive vontade de extrapolar as práticas } \\
\text { tradicionais. }\end{array}$ \\
\hline Professora F & Formação Pedagógica \\
\hline Professor S & $\begin{array}{l}\text { Sim, sempre precisamos estar atualizados na profissão, para lidar com pessoas! Nos } \\
\text { últimos anos fiz 3 especializações }\end{array}$ \\
\hline
\end{tabular}

Para fins de análise, destacamos as contribuições da professora J quando esta afirma que inicialmente não possuía formação no campo educacional e que acabou se tornando docente na Educação Profissional.

Nesse trecho de sua fala, a professora evidencia a realidade de muitos professores atuantes na Educação Profissional, pois é comum nessa modalidade de ensino os professores não possuírem formação pedagógica ao ingressarem no exercício da docência. Desse modo, a busca pela formação na área da educação se dá muitas vezes após o início do exercício docente como salienta a professora J ao afirmar ter realizado formação pedagógica e o quanto esta formação auxiliou na sua prática docente evidenciando as diferentes formas de avaliação que aprendeu e o desejo que a acompanha em ir além das práticas de ensino tradicionais.

Ainda que culturalmente no cenário educacional brasileiro a formação pedagógica dos profissionais da Educação Profissional tenha ficado em segundo plano, tendo em vista a carência de políticas públicas de formação específica para atender complexidade dessa modalidade de ensino apontada por Oliveira (2010), é possível observar na fala dos professores participantes o desejo de evoluir e transformar-se pessoal e profissionalmente.

É notório o quanto essa formação é capaz de contribuir para a reflexão desses professores quanto aos desafios de atuar com pessoas como explica o professor $\mathbf{S}$ quanto a importância da busca por atualização e qualificação profissional para o ofício docente.

O percurso profissional a que se veem os professores logo no início da carreira docente é pautado sobretudo da tomada de consciência, de apropriação de "ser" docente e, principalmente, de pertencimento que se fundem na instrumentalização do trabalho diário.

O crescimento profissional e evolução pessoal desses profissionais fomentam o processo dinâmico de formação identitária, no qual os sujeitos ao longo de suas trajetórias se formam e se transformam através da interação Nóvoa (2007).

\section{SOBRE AS POSSÍVEIS TRANSFORMAÇÕES IDENTITÁRIAS}

Ao compreendermos o ofício docente como um percurso de formação e transformação pessoal e profissional, estamos a afirmar que essas trans(formações) se constituem também de aspectos pessoais e identitários desses sujeitos através da apropriação subjetiva da identidade social Nóvoa (2007). 
A seguir apresentamos as contribuições dos professores participantes ao que se refere a realização de formação pedagógica e se acreditam que foi relevante para construção e/ou modificação da sua identidade docente.

\begin{tabular}{|l|l|}
\hline Professora J & $\begin{array}{l}\text { Sim, o PARFOR. Foi relevante porque como tive acesso a diferentes formas de } \\
\text { estratégias, técnicas, dinâmicas, me senti mais fortalecida e empoderada no meu fazer } \\
\text { docente. }\end{array}$ \\
\hline Professora F & $\begin{array}{l}\text { Sim, o PARFOR. Foi relevante porque como tive acesso a diferentes formas de } \\
\text { estratégias, técnicas, dinâmicas, me senti mais fortalecida e empoderada no meu fazer } \\
\text { docente. }\end{array}$ \\
\hline Professor S & $\begin{array}{l}\text { Sim. A do PARFOR, que nos proporcionou a convivência com outros demais colegas, a } \\
\text { compartilhar práticas e a desenvolver uma nova visão de alguns aspectos } \\
\text { pedagógicos. }\end{array}$ \\
\hline
\end{tabular}

Observamos nos relatos dos professores, a relevância que estes dão ao processo de formação pedagógica e formação continuada dos profissionais de educação. É no tocante de seus dizeres que se potencializa o trabalho do professor. Podemos destacar, mais especificamente, a fala da professora J, quando essa nos diz sentir-se mais segura e em sua atuação docente e, ao expressar tal sentimento, a professora nos remete a descoberta de si o do seu papel como educadora frente aos desafios e transformações que a profissão docente acarreta.

As construções que ocorrem dentro da profissão perpassam os saberes já adquiridos na academia, esses saberes nem sempre são base para o exercício da profissão. Dessa forma, emergem inquietações levando os indivíduos ao movimento e constante reflexão de sua prática percebendo que o ofício docente está muito além do ato de ensinar.

Estando assim, ancorado a outros saberes pertinentes ao trabalho com outras pessoas, reforçando uma formação docente pautada na partilha de conhecimentos, sentimentos, anseios e incertezas da profissão como evidenciado pelo professor $\mathrm{S}$ ao referir-se aos aprendizados adquiridos na vivência e troca de experiências com colegas de profissão.

Fica evidente, na voz dos professores, a complexidade da atuação docente no tange aos aspectos de apropriação de um discurso e uma postura própria da profissão e que esta apropriação está sobretudo ligada a interação constante e nas trocas com colegas de profissão e os próprios alunos a que se dedicam os professores, esta observação aparece mais claramente nas palavras de Tardif:

É através das relações com os pares e, portanto, através do confronto entre os saberes produzidos pela experiência coletiva dos professores, que os saberes experienciais adquirem uma certa objetividade: as certezas subjetivas devem ser, então, sistematizadas a fim de se transformarem num discurso da experiência capaz de informar ou de formar outros docentes e de fornecer uma resposta para seus problemas. (TARDIF, 2014, p.52)

Nesse sentido, podemos compreender que os professores no decorrer de suas carreiras vivenciam distintas transformações e que, através dessas, são capazes de agregar sentidos e significados a sua prática, portanto, é na interação entre professores e professores mais experientes ou entre professores e alunos que os saberes partilhados conduzem ao conhecimento e produção de novos saberes. 
Tais processos de transformação realizados na coletividade que a atuação docente propõe compreende os sujeitos em sua multiplicidade, movidos, formados e transformados continuamente de acordo com os contextos pelos quais são atravessados (HALL, 2011). Ou, ainda, podemos inferir que durante o percurso os sujeitos atravessam e são atravessados de distintas identidades que se modificam conforme os tempos, espaços e realidades vivenciadas durante suas trajetórias de vida pessoal e profissional.

Cabe-nos ressaltar ainda que na medida em que os professores tomam consciência do seu protagonismo frente a sua formação e o quanto essa formação é relevante para a constituição de sua personalidade profissional que, consequentemente, reflete na prática docente é que buscamos a contribuição dos professores participantes da pesquisa sobre o quanto a formação pedagógica vem a proporcionar mudanças na sua prática docente.

\begin{tabular}{|l|l|}
\hline Professora J & $\begin{array}{l}\text { Sim, pois a partir dela fui implementando novas práticas, avaliativas inclusive, } \\
\text { utilizando portfólios, jogos pedagógicos etc. }\end{array}$ \\
\hline Professora F & Não. \\
\hline Professor S & $\begin{array}{l}\text { Sim. Deu uma base teórica bem fundamentada para alguns pontos que eram } \\
\text { realizados mais instintivamente no diário da sala de aula. }\end{array}$ \\
\hline
\end{tabular}

$\mathrm{Na}$ sequência, destacamos as contribuições da professora J e do professor $\mathrm{S}$, por evidenciarem em suas falas a relevância que a formação pedagógica tem no seu fazer docente e o quanto esta contribuiu para a tomada de consciência do papel do professor se reinventando dentro da profissão, conforme a professora J destaca, a introdução de práticas inovadoras, tanto no cotidiano de sala quanto nos processos avaliativos.

O professor S ressalta o aporte teórico da formação pedagógica como parte fundamental a sua prática, nos afirmando que aspectos do cotidiano de sala eram realizados de forma instintiva e hoje sente-se mais preparado em uma prática bem fundamentada teoricamente.

Tais contribuições são valiosas para este estudo, visto que ao compreenderem a necessidade de se preparar não apenas para o exercício da profissão, mas também para os desdobramentos que existem dentro da profissão é que estamos a falar de professores conscientes do seu ofício e protagonistas de sua formação e atuação

\section{SOBRE OS MODELOS DE LETRAMENTO E A PRÁTICA PEDAGÓGICA}

Nesta seção apresentamos a questão dos letramentos frente a prática pedagógica dos professores participantes desta pesquisa como forma de entender como os professores da Educação Profissional concebem o processo de apropriação dos letramentos e até que ponto os letramentos fazem parte da sua prática educativa.

Nesse sentido, trazemos para o foco desse estudo o letramento ideológico proposto por Street (1995) por caracterizar de forma mais fidedigna o processo de transformação profissional vivido pelos professores participantes. O modelo ideológico de letramento se pauta na pluralidade de contextos a que estamos inseridos no decorrer da trajetória pessoal e profissional e, portanto, confere a cada contexto uma forma de conhecer, ler e interpretar o mundo evidenciando os aspectos, culturais, econômicos e sociais que condicionam as relações de poder em sociedade. 
Referente as principais mudanças que a formação pedagógica trouxe para sua prática docente, obtivemos as seguintes elucidações dos professores.

\begin{tabular}{|l|l|}
\hline Professora J & $\begin{array}{l}\text { Mudanças em termos de propostas de atividades diárias e avaliativas, e também de } \\
\text { aprender a olhar o processo e não o resultado ou produto final, como nos acostumamos } \\
\text { pelas práticas tradicionais, com vistas em uma educação bancária. Procuro estimular o } \\
\text { protagonismo dos alunos, envolvê-los nos processos... }\end{array}$ \\
\hline Professora F & Não mudou em nada. A prática docente diária se distancia muito das teorias. \\
\hline Professor S & $\begin{array}{l}\text { Como falado na questão anterior, a formação contínua mostra uma visão diferente e } \\
\text { diferenciado das práticas. }\end{array}$ \\
\hline
\end{tabular}

Os professores participantes desta pesquisa explicam as muitas mudanças que a formação pedagógica trouxe no fomento de suas práticas educativas, contribuindo para a transformação do seu olhar para o ensino como um processo rico permeado de relações e não focado no resultado como nos evidencia a professora $\mathrm{J}$.

A professora refere-se às práticas tradicionais que foram parte de sua formação escolar e que hoje percebe o processo como um todo, visando proporcionar aos alunos vivencias significativas, estimulando o protagonismo dos discentes.

Também explicitado pelo professor $\mathrm{S}$, ao afirmar que a formação continuada lhe trouxe aprendizados fundamentais para a realização de práticas pedagógicas diferenciadas que muito contribuem para 0 trabalho desenvolvido junto aos alunos.

Assim sendo, podemos observar que há na fala dos professores o uso do letramento ideológico para compor um trabalho docente contextualizado, crítico e reflexivo, buscando na e através das interações modos distintos de compreender o mudo.

Assim nas palavras de Fischer:

Aprender nos e com os procedimentos característicos de uma comunidade, e não apenas aprender sobre eles, abre a possibilidade de os sujeitos adotarem perspectivas, visões de mundo críticas e reflexivas próprias dessa comunidade. Gee (1999) chama atenção para uma faceta da imersão - não basta se inserir em práticas de letramento de uma dada comunidade com os olhos fechados ou apenas instruir os sujeitos a reproduzir ações, discursos, de forma a-crítica. As instruções explícitas sobre o funcionamento de uma dada prática podem e muito contribuir para desocultar muitas estruturas de poder. Pode haver interações diversas, que abrem espaços para que os sujeitos mudem, alternem os papéis, como em uma aula do curso de Letras, em que o professor viabiliza a voz aos alunos ou viabiliza que eles assumam o papel de professor em uma dada atividade didática. (FISCHER 2007, p. 30).

Ao pensar na inserção em um determinado grupo, sem nela haver real intencionalidade é que por vezes nos deparamos com profissionais que de fato assumem o ofício docente, sem refletir sobre as múltiplas faces dessa profissão.

Ainda que estejam imersos e sejam então capazes de agir e reproduzir discursos, permanecem presos a outros modos, tempos e espaços que os impossibilita de construir uma nova identidade docente, como podemos destacar na fala da professora $\mathrm{F}$.

A professora expressa em sua fala não ter vivenciado mudanças no seu fazer docente após a realização da formação pedagógica, acreditando que as teorias muito se deslocam da prática docente. 
Tal característica é observada no modelo autônomo de letramento ainda muito presente nas instituições de ensino e se dá através de práticas descontextualizadas e padronizadas, na qual não há relação com o contexto vivenciado, apenas regras e habilidades técnicas a serem seguidas pelos sujeitos.

Diante do exposto, fica evidente que os professores participantes desse estudo, ainda que em trajetórias diferentes, em algum momento passaram pelo processo de reflexão sobre a profissão docente e buscaram meios de aperfeiçoamento profissional através de formação continuada para darem conta do seu ofício, contudo nem sempre temos os mesmos resultados. Os sujeitos, ainda que imersos aos mesmos contextos, serão "tocados" de distintas formas, ou ainda, não serão atravessados de transformações, como podemos observar mais claramente na voz da professora $\mathbf{F}$ "Não mudou em nada".

Com relação ao desenvolvimento do trabalho no que se refere as atividades, leituras, seminários, provas, aporte teórico e prático, obtivemos as seguintes contribuições dos professores.

\begin{tabular}{|l|l|}
\hline Professora J & $\begin{array}{l}\text { As aulas em geral envolvem trabalhos em grupos, procuro valorizar a cooperação e } \\
\text { estimular os diálogos; aulas expositivas dialogadas, rodas de conversa, seminários, } \\
\text { leituras de textos e construção de jogos por parte dos próprios alunos que aplicam estes } \\
\text { jogos na turma, com base nos textos e debates de sala de aula; provas tenho procurado } \\
\text { abolir da minha prática, porque em geral utilizo as próprias atividades do dia a dia para } \\
\text { avaliar meus alunos, sua participaçãa, seu envolvimento... os trabalhos avaliativos com } \\
\text { maior peso são em grupo, com critérios estabelecidos que valorizem o processo e não } \\
\text { apenas o resultado final. Em geral alguma atividade de registro escrito individual apenas } \\
\text { para buscar identificar como aquele aluno está percebendo a dinâmica das discussões } \\
\text { e dos textos trabalhados em aula, para identificar alguma questão mais específica como } \\
\text { uma dificuldade na interpretação, na escrita... }\end{array}$ \\
\hline Professora F & $\begin{array}{l}\text { Sempre quando organizo uma prática, lembro de alguns professores e tento não ser } \\
\text { igual. Sempre busco algo que tenha "utilidade" na vida do aluno. Ele precisa conectar o } \\
\text { conteúdo com a própria vivência. Eu invisto muito em práticas diferenciadas. }\end{array}$ \\
\hline Professor S & $\begin{array}{l}\text { Por ser professor de uma área muito prática e com um contexto vivenciado pelos alunos, } \\
\text { além da base teórica que é mostrada e bem fundamentada, é trabalhado muito a } \\
\text { experiência prática de cada aluno, bem como discussões abertas dos temas, trabalhos } \\
\text { também sobre estas experiências, além das provas, que são parte obrigatória }\end{array}$ \\
\hline
\end{tabular}

De forma geral, os professores aqui descrevem seus fazeres pautados nos aprendizados adquiridos durante toda sua trajetória pessoal e profissional, mas, sobretudo ressaltam as inúmeras relações e interações vividas no percurso da carreira docente ainda que essas relações não tenham sido positivas, ganham maior destaque na fala da professora $\mathrm{F}$ ao reportar-se a outros professores que fizeram parte de sua caminhada escolar, que tenta não reproduzir aspectos negativos que Ihe fora apresentado durante sua escolarização.

Portanto dedica-se em construir uma prática educativa reflexiva e inovadora, acreditando que o aprendizado acontece quando o aluno consegue relacionar o conteúdo com a sua realidade, em outras palavras podemos entender que o aprendizado acontece quando professores e alunos se empenham em dar sentido e significado ao conhecimento.

É por meio dos diferentes pensares aqui expostos que cabe-nos destacar a fala das professoras J quando esta diz fazer uso de práticas dinâmicas como aulas expositivas, rodas de conversa, seminários, valorizando a interação e cooperação dos alunos na construção de materiais de apoio 
e jogos, avaliando diariamente os aprendizados em grupo e individualmente, evitando o uso de provas como método de avaliação.

Essas palavras ganham maiores significados dentro das discussões sobre os letramentos, pois estão carregadas de sentidos que a professora foi agregando ao seu trabalho ao logo do tempo. Esses sentidos estão ancorados aos distintos contextos a que pertence e que refletem no seu fazer docente, bem como as relações que estabelece no convívio e interação com os alunos.

Nessa direção, na voz dos professores $S$, podemos constatar a busca por novos meios de agir e interagir na docência, através de aulas práticas, reflexivas e contextualizadas a realidade dos alunos propondo discussões abertas sobre as temáticas e leituras que fomentam a prática vivenciada pelos alunos nos diferentes contextos a que pertencem.

Ainda que na procura de qualificação para o exercício da docência os profissionais sejam atravessados por transformações, os professores ainda enfrentam um outro desafio na carreira, que é a luta pela quebra de barreiras quanto aos processos avaliativos existentes nas escolas de um modo geral. Reinventar-se na profissão, dar conta dos desdobramentos que a profissão docente acarreta, vivenciar distintos papéis e aprender e ensinar na interação com os outros, são algumas características pertinentes ao ofício desse profissional. Nesse sentido, Silva afirma

É possível, então, entender a atuação de cada um na prática pedagógica exercida na escola. Cada professor acaba por introduzir sua individualidade na construção dos saberes, o que traz a multiplicidade de olhares contribuindo para a ampliação das possibilidades e construção de outros novos saberes. Portanto, durante a formação dos professores, é preciso levar também em consideração os saberes do cotidiano, para que se estabeleça forte vínculo entre os saberes e os fazeres, sem deixar de reconhecer que o professor pode se constituir sujeito do conhecimento. (SILVA 2015, p.36).

Através das palavras de Silva, podemos compreender melhor as múltiplas faces que compõem o fazer docente e o quanto este é impregnado de significados e vivencias ao logo do percurso percorrido e vivido tão intensamente pelos profissionais que assumem o papel de educador e assumindo tal ofício compreendem a complexidade da profissão.

Assim permanecem na busca e na construção de novos conhecimentos junto a outros docentes, aos discentes que são parte fundamental no processo de construção de sua prática educativa reflexiva e contextualizada, fazendo da escola um espaço não apenas de formação, mas de produção de saberes múltiplos.

Nesse estudo, os professores participantes evidenciaram aspectos característicos do letramento autônomo, ao se reportarem as práticas tradicionais vivenciadas por estes enquanto alunos no processo de escolarização e alfabetização ou ainda na postura adotada por alguns ao afirmarem não terem sido atravessados de transformações durante o percurso de formação pedagógica, estando presos em outros tempos e espaços que os impedem de construírem uma identidade docente.

\section{CONSIDERAÇÕES FINAIS}

O objetivo geral constitui-se em reflexionar sobre as práticas de letramentos passíveis de transformações identitárias de profissionais que atuam como docentes na Educação Profissional. Os 
objetivos específicos são: (a) identificar os caminhos de formação inicial e continuada percorridos pelos docentes; (b) constatar as possíveis transformações identitárias dos docentes com relação à prática docente; (c) reconhecer qual/is modelo/s de letramentos estão presentes nas práticas pedagógicas.

A formação docente contínua e permanente dos professores é uma temática bastante discutida no cenário educacional brasileiro, no entanto ao considerarmos formação pedagógica de professores atuantes no Educação Profissional, nos deparamos com inúmeros desafios dentro dessa modalidade de ensino, assim sendo, buscamos através deste estudo evidenciar os percursos vividos por estes profissionais ao reflexionarmos sobre as práticas de letramentos passíveis de transformações identitárias de profissionais que atuam como docentes no ensino técnico/profissionalizante.

Através das contribuições dos professores participantes dessa pesquisa, foi possível compreender a formação pedagógica como um caminho longo e complexo, permeado de incertezas que refletem diretamente no discurso e apropriação do discurso próprios da profissão. Desta forma, podemos entender que a formação pedagógica implica sobretudo na reflexão da própria atuação e não apenas na transmissão e reprodução do conhecimento.

Tal reflexão nos remete as múltiplas transformações que ocorrem nesse processo de apropria ção e pertencimento dentro da profissão caracterizando de forma mais sensível a formação de professores dentro da profissão, podemos dizer em outras palavras, que a formação docente é concebida dentro das interações e trocas de experiências com outros professores ou ainda com os alunos, sendo este, parte fundamental no processo de formação dos professores.

A formação de professores dentro da profissão é também uma formação de vida. Nos dizeres dos professores podemos evidenciar as distintas transformações vividas por eles dentro e fora da atuação docente, compreendendo que durante o percurso atravessaram e foram atravessados de grandes transformações identitárias que refletem diretamente em sua ação educativa, sendo assim um espaço ocupado por indivíduos conscientes do seu papel na edificação profissional, humana e social de si e dos outros.

Nesse sentido, é possível evidenciar que os caminhos percorridos na caminhada escolar, acadêmica, cursos de formação pedagógica ou ainda percursos de vida dos professores participantes estão impregnados de sentidos e significados que foram agregando no decorrer de suas trajetórias. É através das interações vividas por eles dentro dos distintos contextos e realidades a que pertencem é que se constituem protagonistas de sua formação.

Diante do exposto, é que se configuram mais expressamente a presença dos letramentos na trajetória dos profissionais atuantes na Educação Profissional participantes desse estudo, pois estes se constituem na instrumentalização da prática educativa e na reflexão sobre a prática.

Por outro lado, deparamo-nos com o olhar sensível e reflexivo a que se propõe o letramento ideológico, quando retratado de forma singular pelos educadores ao evidenciarem as inúmeras descobertas que realizam cotidianamente dentro da profissão, oportunizando um aprendizado reflexivo e singular aos alunos e com estes re (constroem) novos saberes se constituindo protagonistas de sua formação. 
Concluímos o presente estudo acreditando na potência da formação pedagógica, fomentada na interação e na partilha de saberes entre os profissionais, fazendo da escola um espaço de reflexão e sobretudo um espaço de produção de saberes compreendendo que tais conhecimentos estão diretamente ligados aos múltiplos contextos que se fundem na atuação docente.

\section{REFERÊNCIAS}

BRASIL. Lei de Diretrizes e Base da Educação Nacional. Lei número 9394, 20 dezembro de 1996.Disponível em:

$<$ http://www.planalto.gov.br/ccivil_03/_Ato20112014/2013/Lei/L12796.htm\#art1>

BAUMAN, Z. Legisladores e intérpretes: sobre modernidade, pós-modernidade e intelectuais. Tradução de Renato Aguiar. Rio de Janeiro: Zahar, 2010.

DUBAR, C. A crise das identidades: a interpretação de uma mutação. Porto: Edições Afrontamento, 2006.

FISCHER, Adriana. A Construção dos Letramentos na Esfera Acadêmica. Repositório institucional $\quad$-UFSC, 2007.2 Disponível em: <http://repositorio.ufsc.br/xmlui/handle/123456789/89764> acesso em: 12/08/20.

FONSECA, J. J. S. Metodologia da pesquisa cientifica. Fortaleza: UEC, 2002.

GATTI, B. A. Os professores e suas identidades: o desvelamento da heterogeneidade, In: Cadernos de Pesquisa, São Paulo, n.98, p. 85-90, ago, 1996. Disponível em: <http://publicacoes.fcc.org.br/ojs/index.php/cp/article/view/798/809>. Acesso em: 31/10/19.

GERHARDT, T. E.; SILVEIRA, D. T. Metodos de pesquisa. Métodos de pesquisa/[organizado por] Tatiana Engel Gerhard e Denise Tolfo Silveira; coordenado pela Universidade Aberta do BrasilUAB/UFRGS e pelo Curso de Graduação Tecnológica- Planejamento e Gestão para o Desenvolvimento Rural da SEAD/UFRGS. -Porto Alegre: Editora da UFRGS, 2009, 120 p.: il.; 17,5x 25 cm.

GIL, Antonio Carlos, 1946- Como elaborar projetos de pesquisa/ Antonio Carlos Gil.-.ed.- São Paulo: Atlas, 2002

HALL, S. A identidade cultural na pós-modernidade/ Tradução Tomaz Tadeu da Silva, Guaracira Lopes Louro - 11. Ed. 1. Reimp. - Rio de Janeiro: DP\&A, 2011.

Quem precisa de identidade? In: SILVA, Tomaz Tadeu da (Org.). Identidade e Diferença: a perspectiva dos Estudos Culturais. Petrópolis, RJ: Vozes, 2007. P. 103-133.

KATO, M. No mundo da escrita: uma perspectiva psicolingüística. São Paulo: Ática, 1986.

KLEIMAN, A. B. Modelos de letramento e as práticas de alfabetização na escola. In: KLEIMAN, A. B. (Org.). Os significados do letramento: uma nova perspectiva sobre a prática social da escrita. Campinas, SP: Mercado de Letras, 1995. p. 15-61.

NÓVOA, António. Para uma formação de professores construída dentro da profissão. Revista de Educacíon, [S. I], n. 350, $2009 . \quad$ Disponivel em: <http://www.revistaeducacion.educacion.es/re350/re350_09por.pdf> acesso em: 08/08/19.

NÓvOA, António et al. Vidas de Professores. Org. de António Nóvoa. Editor: Porto Editora, 2007. 
OLIVEIRA, M. R. N. S. de. A formação de professores para a educação profissional. In: DALBEN, A. L.; DINIZ, J.; LEAL, L.; SANTOS, L. (Org.). Coleção Didática e Prática de Ensino. Belo Horizonte, Autêntica, 2010.

OLIVEIRA, M. R. N. S. de. Formação e profissionalização dos professores do ensino técnico. Educação e Tecnologia, Belo Horizonte, v.11. n.2, p.3-9, jul./dez. 2006.

PRADANOV, Cleber Cristiano. Metodoligia do trabalho científico [recurso eletrônico]: método e técnicas da pesquisa e do trabalho acadêmico/ Cleber Crisitano Pradanov, Emani Cesar de Freitas. 2. Ed. - Novo Hamburgo: Feevale, 2013.

PROENÇA, M. G. S.; MELLO, L. S. Ser professor: identidade histórica que se constrói no desempenho dos papéis. In: Série Estudos - Periódico do Mestrado em Educação da UCDB. Campo Grande- MS, n028, p 53-64, jul./dez. 2009. Disponível em: <https://www.serie-estudos.ucdb.br/serieestudos/article/view/166> acesso em 08 jul. 2020.

SILVA, Veronice Camargo. Relações entre letramento acadêmico no estágio supervisionado e práticas de ação docente na voz do aluno-professor. Pelotas: UCPEL, 2015. $160 f$.

STREET, B. V. Literacy in theory and paractice London. Cambridge University Press, 1984.

Social Literacies. Critical Approaches to Literacy in Development, Ethnography and Education. Harow: Pearson, 1995.

Abordagens alternativas ao letramento e desenvolvimento. Teleconferência Brasil sobre o letramento, outubro de 2003.

Literacy in theory and paractice London. Cambridge University Press, 2006.

TARDIF, Maurice Saberes docentes e formação profissional/ Maurice Tardif. 17.ed.-Petrópolis, RJ: Vozes,2014.

TFOUNI, Leda Verdiani. Letramento e Alfabetização. São Paulo: Cortez, 1995.

Submissão: 04/04/2021

Aceito: 13/07/201 